\title{
Survey on Technology Trends for the Robust HBAC
}

\author{
Parul Aggarwal \\ ECE Department \\ GNDU RC, Jalandhar
}

\author{
Jyoteesh Malhotra, Ph.D. \\ ECE Department \\ GNDU RC, Jalandhar
}

\begin{abstract}
The research work in the area of Human body area channels (HBAC) has grabbed the attention of both academia and researchers due to its numerous possible applications in the field of healthcare, medical and consumer services. Keeping in view the growing interest in the area of HBAC, this paper provides a comprehensive survey on the technology trends for air interface standards. In doing so, various HBAC link setups with different signaling techniques, antenna systems and measurements setups that have been considered in the literature have been investigated in terms of their performance metrics. Moreover, open issues and challenges have been highlighted here to obtain an efficient and robust HBAC.
\end{abstract}

\section{Keywords}

HBAC, signaling techniques, measurement setups, PHY and MAC protocols.

\section{INTRODUCTION}

IEEE 802.15.6 has provided an international standard for a short range i.e. human body range, low power and highly reliable wireless communication with high QoS, data rate and least interference to be used in, on and around human body for addressing the best applications [1], [2]. This communication link setup was thus titled as "Human Body Area Channel". As described in [3],[4], HBAC is a special wireless communication network that is designed and developed for human body to supervise, manage and communicate various signs like temperature, blood pressure and ECG etc. Different sensors installed on human skin or clothes can be used to monitor such signs. A cellular phone can be used to monitor the communication to and from the human body to outside world. It has been employed for services like user identification, wireless headphone, medical treatment like cancer, diabetes, asthma treatment etc.

It was reviewed from [5] that the need for low power consumption, reduced complexity and size of electronic devices has led to rushing demands for wireless communication along human body area. It constitutes wireless personal area networks near and around the human body. The communication devices can be located in, on or near human body within a wireless network to support applications related to medical, healthcare and consumer electronic services by linking body sensors to create a body area network.

The biggest challenge for HBAC [6] is its propagation modeling which can be employed to understand the propagation characteristics in and around the human body. They are also essential criteria for designing antenna system, protocols, front-end RF hardware and the signaling techniques.

HBAC is a rising trend in technology era, so there are many issues and challenges that need appropriate solutions. Thus many efforts have been done and still in progress to overcome those issues and challenges. The following is the survey on various methods and tasks that have been carried out for obtaining robust HBAC.

The aim of writing this paper is to investigate the progression in technology so far for building up an effectual and reliable HBAC. The contribution to this paper is a review of the issues and challenges that have been cited from the literature and to bring up the gaps that need more work to be done.

This paper has been organized as follows. In the next part, the background of HBAC along with its operable frequency bands and channel models has been described. Following it, the work that has been done to analyze and obtain better HBAC models have been discussed. Consequently, the issues and challenges in HBAC link setups that have been investigated from the literature have been given briefly and the last section concludes the paper.

\section{BACKGROUND}

This section briefly describes the important considerations related to physical layer interface for "Human body area channels".

The concept of body area networks was given by Zimmermann in 1996. The IEEE 802.15 Working group developed the IEEE 802.15.6 standard for low power devices and to operate on and around the body. This standard got approval in 2012 for wireless communication in HBAC. As compared to classical wireless communications, for body area communication, the human body acts as a communication medium either passively or favorably. The required knowledge about BAN has been expanded from wireless communications to bio-electromagnetics. The first author in body area communications had background in mobile communications and personal computer communication, led to research on body area networks in 2005. Thus it was analyzed that the most prior step to explore and analyze HBAC is channel modeling [5]. The important terms and aspects that are to be considered for channel modeling are briefly given as:

\subsection{Frequency Bands}

HBAC modeling can be done in different frequency bands [1], [5], [7], [8] which can be categorized as follows:

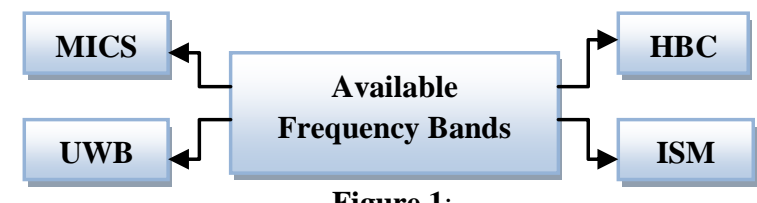

Figure 1:

UWB: Ultra wide band, ranges from 3.1 to $10.6 \mathrm{GHz}$ and it can be employed for both in-body and on-body communication

MICS: Medical implant communication service band that operates between 402-405 MHz and can be employed for inbody communication 
ISM: Industrial, scientific and medical band in $430 \mathrm{MHZ}$ and $2.4 \mathrm{GHz}$ band

HBC: Human body communication band from $10-50 \mathrm{MHz}$ that provides possibility for low data rate on-body communication.

\subsection{Modulation/Demodulation}

The important digital methods for modulation include amplitude shift keying (ASK), frequency shift keying (FSK) and phase shift keying (PSK) and these are well suitable for MICS, ISM or HBC band communication. There is IR-UWB and multi-band orthogonal frequency division multiplexing (MB-OFDM) for UWB and the UWB receivers are usually based on pulse energy detection or correlation demodulation with template waveform. MIMO (Multiple inputs multiple outputs) can be combined with UWB for providing good performance. Modulations like OOK, M-PSK and BPPM are employed to analyze UWB band [5], [9], [10].

\subsection{Channel Models}

Based on positions of three types of nodes i.e. Implant node, body surface node and external node, different links constituting different scenarios between these nodes have been grouped to form different channel models. There are mainly four channel models designed for different frequency bands i.e. CM1, CM2, CM3 and CM4 where CM refers to channel model as described in [7], [11], [12], [8] i.e.

Table.1. HBAC Models

\begin{tabular}{|c|c|c|}
\hline Scenarios & Channel Model & Frequency band \\
\hline $\begin{array}{l}\text { S1(Implant to } \\
\text { implant) }\end{array}$ & CM1 & $402-405 \mathrm{MHz}$ \\
\hline $\begin{array}{l}\text { S2(Implant to } \\
\text { body surface) }\end{array}$ & $\mathrm{CM} 2$ & $402-405 \mathrm{MHz}$ \\
\hline $\begin{array}{l}\text { S3 (implant to } \\
\text { external) }\end{array}$ & $\mathrm{CM} 2$ & $402-405 \mathrm{MHz}$ \\
\hline $\begin{array}{l}\text { S4 (Body } \\
\text { surface to body } \\
\text { surface) }\end{array}$ & CM3 (LOS) & $\begin{array}{l}13.5,50,400,600, \\
900 \mathrm{MHz} \\
2.4,3.1-10.6 \mathrm{GHz}\end{array}$ \\
\hline $\begin{array}{l}\text { S5(Body } \\
\text { surface to body } \\
\text { surface) }\end{array}$ & CM3 (NLOS) & $\begin{array}{l}13.5,50,400,600 \\
, 900 \mathrm{MHz} \\
2.4,3.1-10.6 \mathrm{GHz}\end{array}$ \\
\hline $\begin{array}{l}\text { S6 (Body } \\
\text { surface to } \\
\text { external) }\end{array}$ & CM4 (LOS) & $\begin{array}{l}900 \mathrm{MHz}, 2.4,3.1-10.6 \\
\mathrm{GHz}\end{array}$ \\
\hline $\begin{array}{l}\text { S7(Body } \\
\text { surface to } \\
\text { external) }\end{array}$ & CM4 (NLOS) & $\begin{array}{l}900 \mathrm{MHz}, 2.4,3.1-10.6 \\
\mathrm{GHz}\end{array}$ \\
\hline
\end{tabular}

\section{LITERATURE SURVEY}

HBAC is a wide area to explore for and thus numerous techniques have been followed to obtain an effectual system. Different operating environments lead to differences between wearable BAN and implant BAN or on and in-body communications thus forming channel models.
A channel model is a foremost step to investigate body area communication. This theory can be presented in a comprehensive survey of technology trends in the context of body area communications.

Wideband PHY is UWB technology with IR-UWB that is based on transmission of either a single pulse (new paradigm) or a burst of pulses (legacy) per information symbol and FMUWB is combination of CP-GFSK and wideband FM [1]. It has also featured about MAC being characterized with its strong security, macroscopic and microscopic power management supporting QoS. For medium access, four access methods have been suggested i.e. random access, improvised access, scheduled access, and unscheduled access. Robust security solutions have been provided like

1) Master key generation

2) Temporal key creation/distribution

3) Data authentication/encryption.

A GFSK based, simple and power efficient PHY is suggested as a narrowband PHY solution which can be operated in MICS and WMTS bands. GFSK is implementable due to its low cost and low power consumption with improved technology. It has high power efficiency as it can employ a nonlinear amplifier at transmitter and can provide noncoherent detection without PLL at receiver and shortening the length of preamble. FSK being a robust signaling technique against bad channel conditions observed in medical scenes like erroneous channels, fading and shadowing and immediate blocking, is appropriate for medical applications [9].

The literature study from [10] suggests a unique robust design for HBAC PHY. Pulsed chirp UWB because of its good performance in HBAC has been proposed for PHY. For medical and non-medical purpose, hybrid type of ARQ and FEC is suggested to make it more reliable and for low power consumption. It has discussed about Direct sequence UWB (DS-UWB) which employs spread sequence to distinguish many users but due to spreading gain, it cannot tolerate nearfar problem, and Chirp-on UWB (CO-UWB) having different frequency for multiple nodes can easily sweep frequency among UWB and tolerates near-far problem but it cannot distinguish different BAN's.

Error controlling can be done using Forward error control (FEC) and automatic repeat request (ARQ). The hybrid of FEC and ARQ is employed for both error correction and detection. This scheme can improve BER by $0.5 \mathrm{~dB}$ and throughput as $18-40 \%$ with FEC.

Also it has given the background for MAC design in HBAC that integrates medical science and wireless technology and it focuses probably on implant BAN. It has proposed MAC protocol to minimize the thermal influence over human body. And this has been implemented as by forming cluster leader switch in which thermal influence has been controlled by switching to access controlling task among multiple FFD (full function device) nodes which are cluster leaders and obstructs increase in human body temperature.

Literature in [13] suggests that MIMO+UWB provide improvement in terms of SNR. 802.15.4a channel model was based on SISO, thus it was extended to MIMO technique. It was a challenge for HBAC. UWB and high complexity of MIMO needed compromise. 
The major factors responsible for energy waste in HBAC models are collision, idle listening, over hearing, over emitting, etc. The power saving approaches towards MAC in HBAC has been suggested i.e. channel polling (Low power listening), scheduled contention, TDMA which can be contention free or cluster based [14]. It has recommended that hybrid approach is best suitable for diverse HBAC scenario. For in-body scenario, TDMA based protocols are suitable whereas CSMA based protocols are best for on/out body operations.

In [4], UWB based HBAC's, employing modulations among OOK, BPPM, BPSK and DPSK, BER and PER are analyzed. The measurement setup employs channel transfer function over frequency range of 3.4-4.8 GHz with vector network analyzer (VNA). The path loss results gives additional human body losses less than $10 \mathrm{~dB}$ and RMS delay results give maximum delay spread of $40 \mathrm{~ns}$.

This paper categorizes signaling techniques for SC-UWB as one for reducing power consumption like OOK and PPM, and the other for BER improvement like PSK. BPPM and OOK detect non-coherently at receiver whereas BPSK detects coherently which needs short state information for recovering transmitted signals correctly. DBPSK employs differential detection that doesn't need channel state information. It was analyzed that modulation scheme employing non-coherent receiver pays much penalty than coherent detection in its performance value.

An efficient antenna system for robust HBAC network error performance is necessary. It had been analyzed that among all monopoles, micro strip patches, planar inverted F-antennas, loops and dipole antennas, PIFA gives the $2^{\text {nd }}$ best gain performance with high shadowing losses and deteriorating efficiency as compared to monopoles[2]. It has stated that Finite State Markov chains models have been employed on a large scale for error performance modeling in time varying wireless flat-fading channels of communication systems. Diversity can be formed using these.

In [15] for wearable and implantable wireless ban including miniature antennas, static path loss and impulse response models have been presented and UWB transmission is measured using impulse response model. This paper has followed two approaches to model UWB channel i.e. transversal filter model and Poisson process model.

Whereas the measurement setup employing RUSK- Fujutsu channel sounder of $4.5 \mathrm{GHz}, \mathrm{BW}=120 \mathrm{MHz}$ using UWB sky cross antenna have been used to obtain statistical property of dynamic ban channel gain in [16]. It has employed two distribution functions i.e. lognormal distribution function and it has been analyzed that this kind of distribution can show good results for small movements and express still conditions well. Another one was Weibull distribution function that it shows best results for large movements.

The studies were further carried out in [17], where HBAC model is formulated using temporal sliding window for a walking activity in an office scenario considering numerous antennas and positions. The results show that small scale fading follow Rician distribution whereas large scale fading follow lognormal distribution. And it has been analyzed from literature that Rician distribution is adequate for HBAC's.

Based on literature survey done, the issues and challenges that have been reviewed are tabulated as:
Table.2.

\begin{tabular}{|c|c|c|}
\hline Author/Year & Description & $\begin{array}{l}\text { Pros and Cons/Issues } \\
\text { And Challenges }\end{array}$ \\
\hline $\begin{array}{l}\text { Davenport } \\
\text { David, } \\
\text { Hernandez } \\
\text { Marco, et.al/ } \\
\text { Nov 2012 }\end{array}$ & $\begin{array}{l}\text { It introduces to } \\
\text { BAN featuring } \\
\text { UWB-PHY, } \\
\text { HBC and MAC } \\
\text { with security } \\
\text { solutions. }\end{array}$ & $\begin{array}{l}\text { Security solutions } \\
\text { provided. } \\
\text { UWB-PHY need more } \\
\text { modulations for } \\
\text { performance merits } \\
\text { Need for more MAC } \\
\text { protocols. }\end{array}$ \\
\hline $\begin{array}{l}\text { Hara } \\
\text { Shinsuke, } \\
\text { Kenichi } \\
\text { Takizawa, } \\
\text { et.al/ Mar } \\
2009\end{array}$ & $\begin{array}{l}\text { GFSK based } \\
\text { PHY proposed } \\
\text { as narrowband } \\
\text { PHY solution } \\
\text { for MICS and } \\
\text { WMTS bands }\end{array}$ & $\begin{array}{l}\text { Focused on just FSK, } \\
\text { GFSK for only } \\
\text { MICS,WMTS and } \\
\text { ISM bands } \\
\text { Future work on UWB } \\
\text { PHY in UWB band }\end{array}$ \\
\hline $\begin{array}{lr}\text { Kohno } & \text { Ryuji, } \\
\text { Enda } & \text { Koji, } \\
\text { et.al/ } & \text { Mar } \\
2009 & \end{array}$ & $\begin{array}{l}\text { PHY and MAC } \\
\text { designs for both } \\
\text { medical \& non- } \\
\text { medical } \\
\text { applications } \\
\text { have been } \\
\text { discussed }\end{array}$ & $\begin{array}{l}\text { Future work on more } \\
\text { PHY and MAC } \\
\text { proposals to enhance } \\
\text { performance. } \\
\text { Employing multiple } \\
\text { piconets results to } \\
\text { interference } \\
\text { Only medical purpose } \\
\text { protocols }\end{array}$ \\
\hline $\begin{array}{l}\text { Claude } \\
\text { Oestges/ } 2010\end{array}$ & $\begin{array}{l}\text { He has given } \\
\text { communication } \\
\text { theory for } \\
\text { HBAC. }\end{array}$ & $\begin{array}{l}\text { Large path loss, high } \\
\text { data rates, security and } \\
\text { privacy issues are } \\
\text { challenges } \\
\text { Aiming to develop low } \\
\text { power and secure body } \\
\text { sensor networks } \\
\text { Focusing future work } \\
\text { on implants, nano } \\
\text { networks and } \\
\text { interacting with } \\
\text { biological networks. }\end{array}$ \\
\hline $\begin{array}{l}\text { Kenichi } \\
\text { Takizawa, } \\
\text { et.al/ } 2009\end{array}$ & $\begin{array}{l}\text { Performance } \\
\text { evaluation of } \\
\text { HBAC model } \\
\text { with different } \\
\text { signaling } \\
\text { techniques have } \\
\text { been done and } \\
\text { analyzed }\end{array}$ & $\begin{array}{l}\text { Categorized signaling } \\
\text { techniques as one for } \\
\text { reducing power } \\
\text { consumption and other } \\
\text { for BER improvement. } \\
\text { Proposed efficient } \\
\text { antenna system }\end{array}$ \\
\hline $\begin{array}{l}\text { Saeed } \\
\text { Rashwand, } \\
\text { et.al }\end{array}$ & $\begin{array}{l}\text { Channel fading } \\
\text { models and error } \\
\text { performance } \\
\text { metrics of } \\
\text { HBAC } \\
\text { explained }\end{array}$ & $\begin{array}{l}\text { Integrated PHY and } \\
\text { MAC performance } \\
\text { evaluated } \\
\text { Need to generate more } \\
\& \text { new error models }\end{array}$ \\
\hline
\end{tabular}




\begin{tabular}{|c|c|c|}
\hline $\begin{array}{l}\text { Junichi } \\
\text { Takada, et.al/ } \\
2008\end{array}$ & $\begin{array}{l}\text { Static path loss } \\
\text { and impulse } \\
\text { response models } \\
\text { with miniature } \\
\text { antennas are } \\
\text { presented }\end{array}$ & $\begin{array}{l}\text { The ongoing work for } \\
\text { future is on CM2, } \\
\text { CM3 and CM4 }\end{array}$ \\
\hline $\begin{array}{l}\text { Kim Minseok, } \\
\text { Takada } \\
\text { Junichi, et.al/ } \\
\text { Jul } 2008\end{array}$ & $\begin{array}{l}\text { Dynamic } \\
\text { channel } \\
\text { behavior } \\
\text { measurement } \\
\text { using SISO at } \\
4.5 \mathrm{GHz}, \mathrm{BW}= \\
120 \mathrm{MHz}\end{array}$ & $\begin{array}{l}\text { Clearly explains best } \\
\text { fit distributions at } \\
\text { different positions }\end{array}$ \\
\hline $\begin{array}{l}\text { Y.I. } \\
\text { Nechayev, } \\
\text { et.al / } 2009\end{array}$ & $\begin{array}{l}\text { Propagation } \\
\text { measurements } \\
\text { are performed } \\
\text { and fading } \\
\text { models } \\
\text { generated with } \\
\text { different } \\
\text { antenna systems }\end{array}$ & $\begin{array}{l}\text { Channel parameters } \\
\text { with time variation are } \\
\text { studied and aiming to } \\
\text { approach new channel } \\
\text { model by changing } \\
\text { parameters } \\
\text { To describe channel in } \\
\text { terms of dominant ray } \\
\text { power and mean } \\
\text { power scattered from } \\
\text { environment only. } \\
\text { New channels as Belt- } \\
\text { to-head and belt-to- } \\
\text { wrist considered } \\
\text { Presence of number of } \\
\text { cables is a source of } \\
\text { errors. }\end{array}$ \\
\hline $\begin{array}{l}\text { Kyung Sup } \\
\text { Kwak }\end{array}$ & $\begin{array}{l}\text { MAC issues for } \\
\text { WBAN } \\
\text { including major } \\
\text { sources for } \\
\text { energy wastes, } \\
\text { power saving } \\
\text { mechanisms and } \\
\text { MAC } \\
\text { approaches have } \\
\text { been suggested } \\
\text { for body } \\
\text { communications }\end{array}$ & $\begin{array}{l}\text { Mechanisms designed } \\
\text { to maximize network } \\
\text { lifetime } \\
\text { Maximum possible } \\
\text { mechanisms and } \\
\text { protocols for HBAC } \\
\text { proposed taking into } \\
\text { consideration every } \\
\text { technique }\end{array}$ \\
\hline
\end{tabular}

\section{OPEN ISSUES AND FUTURE SCOPE}

Some of the open issues that have been observed through the literature survey are:

1. Networking issues- Data link layer and networking in HBAC need more research to be done. More HBAC specific MAC protocols are needed on DLL to consider body movements i.e. mobility of nodes, heart beat with time synchronization etc. Effective QoS methods are required as that based on body QoS framework. Several mechanisms should be united to get a cross-layer protocol.

2. PHY issues- Though study on electromagnetic wave propagation in and around the human body has been done, but many of the models proposed doesn't consider body movements which affect the signal strength. Thus the technologies like galvanic coupling and information transformation have given good results and need more investigation in this regard.

3. Security and authentication issues- The data being collected by the medical staff from the patient is confidential and its integrity should be maintained. And it is not reliable that authentication and authorization processes could be handled by the person or the staff. Also the network should be available even when no password could be given.

4. Robustness and continuity- The protocols should be designed in a way that if one node doesn't work, then even the network should in an operable condition. To keep the continuity of the process, minimum communication processes should be operated.

5. Performance and characterization- The wide area for research is by using a human body area network and transferring the signal from one body area to another area.

Realizing an error-free $\mathrm{HBAC}$ is a big challenge to develop a reliable communication system without failure or loss of information. Another challenge being faced is developing an antenna-independent channel model to eliminate the effects of transmitting and receiving antennas. It's a challenge to design an antenna system to make radios travel through lossy tissues for in-body communication. Low power consumption and combining sensors and transceiver into a small chip is a continuous challenge. Solving the mutual interference and interference problem is still an open issue to obtain a reliable HBAC. The small network size of HBAC model is a big challenge.

\section{CONCLUSION}

The main aim of this paper is to investigate the various techniques that have been carried out to obtain an efficient and robust HBAC models. The possible strategies have been reviewed and scanned that can be employed to develop a reliable communication system for HBAC. It has been observed that most of the work has been done keeping focus on best possible signaling techniques, measurement setups and protocols for obtaining the desired results. The open issues and observed challenges could be considered as a resource for future work to bring in practical implementation.

\section{REFERENCES}

[1] Davenport David, Hernandez Marco, et.al, November 2011, “IEEE 802.15.6 Tutorial”, IEEE 802.15.6 technical contribution, doc.: IEEE 802.15-11-0826-02-0006.

[2] Saeed Rashwand and JelenaMisi'c, "Channel and Error Modeling for Wireless Body Area Networks".

[3] Deena M. Barakah and Muhammad Ammad-uddin, IEEE 2012, "A Survey of Challenges and Applications of Wireless Body Area Network (WBAN) and Role of A Virtual Doctor Server in Existing Architecture",DOI 10.1109/ISMS.2012.108.

[4] Kenichi Takizawa, Takahiro Aoyogi, and Ryuji Kohno, Member, IEEE "Channel Modelling and Performance Evaluation of UWB based Wireless Body Area Networks", IEEE ICC 2009 proceedings.

[5] Wang Jianqing and Wang Qiong, 2013 "BODY AREA COMMUNICATION- Channel Modelling, Communications and EMC", ISBN 978-1-118-18848-4, IEEE Press. 
[6] L. An, M. J. Bentum,et.al, "Radio Channel Modeling in Body Area Networks".

[7] Sayrafian P Kamran and Yazdandoost K Yekeh, April 2009, "Channel Model for Body Area Network (BAN)", IEEE802.15.6 technical contribution, doc.: IEEE P802.15-08-0780-09-0006.

[8] Yishuang Geng, May 2013, "Modeling of Time-ofarrival for CM4 Body Area Networks Channel- effects of sensor location, human orientation and distance from access point".

[9] Hara Shinsuke, Takizawa Kenichi, et.al, March 2009, "NICT's PHY proposal --- Part 3: Narrowband PHY solution", IEEE802.15.6 technical contribution, doc.: IEEE 802.15-09-0160-00-0006.

[10] Kohno Ryuji, Enda Koji, et.al, March 2009, "YNU's PHY and MAC design for WBAN IEEE P802.15.6", IEEE802.15.6 technical contribution, doc.: IEEE 802.1509-0164-02-0006.

[11] Simon L. Cotton, Raffaele D'Errico, and Claude Oestges, IEEE May 2014, "A review of radio channel models for body centric communications".
[12] AttaphongseTaparugssanagorn and et.al, "Different experimental WBAN channel models and IEEE802.15.6 models: comparison and effects", IEEE.

[13] Claude Oestges, ICTEAM Electrical Engineering, CTW 2010, May 10-12, "Communicating On and Around the Human Body-Results and Challenges in Body Area Networks", University catholliique de Louvaiin, Belgium, online available at www.uclouvain.be/claude.oestges

[14] Kyung Sup Kwak, “WBAN MAC Issues”,Inha University UWB-ITRC.

[15] Jun-ichiTakada, Takahiro Aoyagi, et.al, Oct 2008, "Static Propagation and Channel Models in Body Area", COST 2100 TD (08)639.

[16] Kim Minseok, Takada Junichi, et.al, July 2008, "Statistical Property of Dynamic BAN Channel Gain at 4.5GHz", IEEE802.15.6 technical contribution, doc.: IEEE 802.15-08-0489-00-0006.

[17] Y. I. Nechayev, P. S. Hall, and Z. H. Hu, Jun 2009, "Characterisation of narrowband communication channels on the human body at $2.45 \mathrm{GHz}$," IEEE Microwaves, Antennas \& propagation, Vol. 4, Iss. 6, pp. 722-732, doi: 10.1049/iet-map.2009.0094. 